AUTOR

Irene $\mathrm{M}^{\mathrm{a}}$ Vicente Martín*

Irene.Vicente@EUI.eu

* Doctoranda en Historia y Civilización por el Instituto Universitario Europeo

\section{Una nueva visión de Salvador de Bahía en el periodo colonial: la ciudad desde una perspectiva atlántica}

\author{
Uma nova visão de Salvador da Bahia no periodo colonial: a cidade desde uma \\ perspectiva atlântica
}

A new view of Salvador da Bahia during the colonial period: the city from an Atlantic perspective

SOUZA, E. S.; MARQUES, G.; SILVA, H. R. (orgs.)

Salvador da Bahia: retratos de uma cidade atlântica.

Salvador de Bahia: EDUFBA; Lisboa: CHAM, 2016.

Desde hace ya algún tiempo se viene demandando en los ámbitos académicos americanistas la urgente necesidad de abandonar las interpretaciones duales y simplistas que aún parecen dominar el panorama explicativo del periodo colonial. Para muchos historiadores, la manida distinción entre metrópoli y colonia, tradicionalmente empleada para explicar la configuración, el desarrollo y el posterior declive de los diversos sistemas implantados por los poderes europeos en América, dejó hace décadas de ser válida. Conceptos tales como dependencia, dominación o centro-periferia ya no servían para definir el pasado, y su caducidad originó un interés generalizado por las negociaciones, los conflictos y las interacciones horizontales y transoceánicas que sin duda definían mejor las realidades históricas del periodo colonial. El libro titulado Salvador da Bahia: retratos de uma cidade atlântica (EDUFBA, CHAM, 2016) debe encuadrarse en este contexto historiográfico, pero no tanto como punto de inflexión entre ambas formas de hacer historia, sino más bien como una pequeña muestra de lo que las nuevas metodologías y definiciones son capaces de aportar cuando se aplican al estudio del pasado histórico. Concretamente, y en este caso, a la ciudad de Salvador de Bahía durante el periodo colonial y poscolonial temprano.

Siguiendo estas nuevas aportaciones y guiados por un interés común en comprender la complejidad inherente a la formación y primer desarrollo de Salvador de Bahía, los organizadores se plantean en este libro analizar "as interações de que foi o lugar, as relações que a definiram, os vários espaços que investia e a investiam e a sua profunda inscrição tanto no império portugués quanto no Atlântico". Este desafío a las cronologías y los esquemas académicos previamente establecidos hacen de su compilación una propuesta ambiciosa, pero E. S. Souza, G. Marques y H. R. Silva demuestran con la coordinación de este volumen un exquisito manejo de la situación. Conscientes de las dificultades que este enfoque plantea, los historiadores buscan así retratar las diversas instituciones, prácticas y representaciones cuyos escenarios comunes fueron Salvador de Bahía y los múltiples espacios atlánticos con los que estuvo conectada. Una vez leído, el libro no puede considerarse como una monografía sobre la dimensión atlántica de Salvador, sino más bien como un conjunto de planteamientos que cuestionan las formas antiguas de hacer historia y arrojan nuevas líneas de investigación, tomando la ciudad y el océano como escenario de intercambios y transformaciones constantes. 
Elegida esta ciudad por la importancia política, económica y social dentro del imperio portugués de ultramar, el libro Salvador da Bahia: retratos de uma cidade atlántica consta de nueve artículos organizados en tres secciones independientes entre sí. Teniendo en cuenta que el imperio portugués estuvo articulado en torno a la economía de servicios y mercês, la expansión del Cristianismo y, en buena medida, la esclavitud, una lectura pormenorizada del volumen demuestra que los tres apartados responden casi sin fisuras a esta tricotomía constitutiva. Y digo casi sin fisuras porque no es habitual que una obra de estas características presente la unidad y cohesión interna que este libro manifiesta. Gracias a ello, no sólo el texto se vuelve más asequible y equilibrado para el lector, sino que también queda demostrado que la Historia no debe hacerse en compartimentos estancos e impermeables.

La primera de las tres secciones referidas lleva por título Cabeça do Estado do Brasil e emporio universal. En ella G. Marques, T. Krause, P. Cardim y A. P. Sousa abordan el papel de Salvador como ciudad imperial en los siglos XVII y XVIII. Según los autores, la creciente circulación de individuos, mercancías e información a través del Atlántico fue determinante para el fortalecimiento de la ciudad dentro del escenario ultramarino, utilizando documentación conservada tanto en Brasil como en Portugal para demostrarlo. Así, G. Marques señala hasta qué punto la constante solicitud de mercês y privilegios por parte de la Câmara a los distintos organismos de la Corona fue fundamental para la consecución de este progreso. De una forma casi similar, T. Krause y P. Cardim estudian el status político de Salvador de Bahía en la Corona portuguesa a partir de las reivindicaciones hechas a ésta por la gente da governança, es decir, por la élite política y económica local. Finalmente, A. P. Sousa trabaja con maestría sobre el progreso económico de la ciudad, llegando a definirla como un nodo cuyo hinterland en el siglo XVII ya atravesaba el mar Atlántico.

La segunda de las secciones, titulada Presentações e práticas numa metrópole religiosa, analiza el significado que tuvo la presencia de la Iglesia y otras instituciones eclesiásticas en el estatus de Salvador dentro del imperio portugués. A este supuesto responden indudablemente los artículos de B. Feitler, E. S. Souza y H. R. da Silva, al analizar el papel de metrópoli religiosa -tanto desde el punto de vista arquitectónico como institucional- que desde muy pronto adquirió Bahía. También demuestran cómo fue la actividad ultramarina y transoceánica de los prelados bahianos, la cual estaba lejos de ser local o circunscrita a la ciudad. Sin embargo, el artículo de L. Reginaldo, si bien se dedica a la Irmandad do Rosário das Portas do Carmo, parece accesorio en esta sección. Quizá por cuestiones de equilibrio editorial los organizadores del volumen decidieron situarlo en este segundo apartado, pero lo cierto es que por temática y cronología se escapa a la unidad del capítulo. Al tener que ver no tanto con la importancia de la institución en sí misma sino más bien con los procesos de construcción de identidad puestos en marcha por los esclavos a lo largo del siglo XVIII, habría tenido mayor coherencia en la siguiente sección.

Como se puede inferir de lo dicho anteriormente, el tercero de los apartados es precisamente el que aborda de manera más cercana la cuestión de la esclavitud, aunque en él se encuentren también otras controversias. Cabe aquí decir que aunque inicialmente el fin principal de este apartado -según la Apresentação- no era atender a la esclavitud propiamente dicha, lo cierto es que dos de los tres artículos que contiene se dedican a ello desde el punto de vista de la movilidad y medro social de los esclavos. Titulado Interações e movilidades numa cidade cosmopolita, su principal objetivo es analizar, a partir de diversas trayectorias individuales, las interacciones sociales que tuvieron lugar en Salvador de Bahía a lo largo del siglo XVIII y XIX, en buena medida determinadas por la presencia de africanos en la ciudad. En general, el tema de la movilidad en Salvador de Bahía queda perfectamente representado por el estudio de G. Raggi sobre la actividad del pintor Antônio Simões Ribeiro en Salvador, poniendo énfasis en cómo diversos actores bahianos utilizaron las pinturas de quadratura como símbolo de status. Al igual que ocurría para el artículo de L. Reginaldo, las premisas y conclusiones de este escrito tienen más que 
ver con la dimensión imperial de la ciudad que con la movilidad del pintor, siendo el único nexo con el resto de la sección la cronología que aborda. Por su parte, las cuestiones verdaderamente relacionadas con la construcción de la identidad social de los esclavos pueden encontrarse en los escritos de J. J. Reis y G. R. Sampaio, ya que en ambos se analizan cuestiones tales como las nações africanas existentes en Salvador, las posibilidades de medro económico de los esclavos, la falta de privilegios y la dependencia social, después de manumitidos, a su antiguo dueño y señor.

Aunque en un primer momento la variedad y amplitud temática y cronológica de los temas abordados puedan dejar en el lector una sensación de dispersión, lo cierto es que sólo tras la lectura del volumen se comprende su unidad. Rehacer la historia de la capital del imperio portugués en Brasil desde el punto de vista de la Historia Atlántica no es tarea fácil, y mucho menos si tenemos en cuenta la amplitud cronológica de tres siglos que los autores han conseguido abordar. Precisamente por ello, cabe insistir que las aportaciones no deben entenderse como compartimentadas ni estancas, sino más bien como breves pinceladas -retratos, si se prefiere- que buscan contribuir a un nuevo dibujo de Salvador de Bahía. El objetivo de los autores, por tanto, queda así alcanzado, ya que las imágenes recogidas contribuyen a un mejor entendimiento de la ciudad y sus conexiones durante el periodo de la colonia.

No obstante, a menudo dichas imágenes son extremadamente técnicas y concretas, creando una distancia entre el volumen y el público no especializado. Concebido para la academia, la temática y la metodología empleadas requieren ciertos conocimientos previos por parte del lector, conocimientos previos acerca de la ciudad de Salvador, de la configuración del imperio portugués y de las nuevas concepciones y metodologías manejadas en la actualidad por los historiadores. Por si esto fuera poco, los artículos son en su inmensa mayoría el resultado de trabajos previos lo que implica que, aparte de la especialización, las conclusiones que presentan no son demasiado innovadoras: los temas tratados apenas rebasan límites cronológicos y conceptuales de los que los autores son especialistas. Así, frente a una preponderancia de temas ya conocidos como la Câmara, el Cabido da Sé y los esclavos africanos, hay una total ausencia de alusiones a las poblaciones indígenas -las cuales también hubieron de construir su identidad-, o al papel que otras naciones -holandeses, españoles, franceses o ingleses- pudieron tener en la configuración de Salvador de Bahía. Del mismo modo es reseñable la falta de estudios dedicados al siglo XVI y primera mitad del siglo XVII, momentos en los que si bien la importancia cosmopolita de la ciudad no fue comparable a la que adquirirá posteriormente, ya se ponen en marcha los cimientos de lo que será una de las mayores ciudades del Atlântico-Sul.

La relativa novedad que supone este tipo de libros para la historia colonial de Salvador de Bahía obliga, sin embargo, a considerar los muchos y abundantes aspectos que hacen de este libro un volumen conveniente, acertado y en buena medida renovador. Su publicación en Open Access refuerza sin lugar a dudas la preocupación de los autores por acercar la historia y sus nuevas aportaciones al mayor número de lectores posible. También el constante diálogo entre las diferentes fuentes primarias y secundarias supone un avance, ya que demuestra tanto la necesidad como la conveniencia de hacer hablar a los diferentes actores que de una forma $u$ otra fueron protagonistas durante el periodo colonial. Sin embargo, el aspecto más positivo y sin duda el más importante es la acentuada atención que algunos artículos dedican a las mujeres y su papel en la sociedad de la ciudad analizada. En un momento como el actual, en el que la sociedad se muestra cada vez más concienciada a favor de la igualdad, que se destaque y se analice el papel de la mujer en una sociedad tan jerárquica y desigual como fue la colonial, es representativo. Los historiadores comienzan así a subsanar las carencias que a este respecto aún presenta la producción historiográfica en general.

En realidad, puede decirse que el volumen en su totalidad es de una calidad considerable, principalmente por su especialización y diversidad. Los múltiples temas que aborda lo convierten en un cuadro complejo, pero que sin duda contribuyen notablemente a comprender "a formação imperial/ colonial da cidade da Bahia em toda a sua complexidade". Es razonable que de una realidad compleja resulte un volumen complejo, pero la profesionalidad, experiencia y capacidad analítica 
de todos los autores han hecho de Salvador da Bahia: retratos de uma cidade atlântica un punto de partida en la nueva interpretación de esta ciudad colonial desde el punto de vista de la Historia Atlántica y la movilidad de sus actores. 